\title{
EFFECT OF WELDING SEQUENCE ON MULTI PASS TEMPER BEAD WELDING JOINT OF PT .INKA BOGIE LRT ON DISTORCTION, MICRO STRUCTURE AND HARDNESS
}

\author{
Moh. M Munir ${ }^{1)}$, Mukhlis ${ }^{2)}$, Imam Khoirul $\mathbf{R}^{3)}$, Hendri $B^{4)}$, M syaiful $A^{5)}$, \\ Erdiyansyah $A^{6}$, and Andi Ari $\mathbf{W}^{7)}$ \\ 1, 2, 3, 4, 5, 6, 7Welding Engineering department, ShipbuildingInstitute of Polytechnic Surabaya, 60111 \\ Surabaya, Indonesia \\ E-mail: m.munir@ppns.ac.id
}

Tel: (031) 5947186, Fax: (031) 5942887

\begin{abstract}
Bogie rail is one of the most important parts, because bogie holds the load on a railway carriage. Because of its, the bogie rail must have good properties and strength. The fabrication process of bogie made with welding, to reduce residual stresses after welding processes, carryout the annealing process. Annealing process or Post Weld Heat Treatment requires a large furnace, large electrical energy, and of course the cost becomes more expensive. In this research, the alternative of welding process with Temper bead welding technique, on the LRT part, joint between plate to plate and plate to round bar. It also performs Post Weld Heat Treatment process on plate to plate connection, and sequence of welding at plate to round bar connection. The result of the research shows that the process of Temper bead welding on the fabrication process of LRT plate to plate and plate to round bar connection, can decrease hardness value, but not significant differences. While the Temper bead welding process can produce the smallest distortion in the bogie LRT. The distortion measurement indicates that, the welding sequence $B$, produce the largest distortion, while the smallest distortion variation is the welding sequence $C$ with temper bead welding.
\end{abstract}

Key words: Welding sequence, Temper bead welding, distortion, hardness

\begin{abstract}
Abstrak
Bogie kereta api merupakan salah satu bagian yang sangat penting, karena bogie menahan beban yang ada pada suatu gerbong kereta api. Karena sifatnya yang sangat penting maka bogie kereta api harus memiliki sifat dan kekuatan yang baik. Bogie hasil proses fabrikasi dengan pengelasan, memerlukan proses annealing untuk mereduksi tegangan sisa yang terjadi. Proses annealing atau Post Weld Heat Treatment tersebut membutuhkan furnace yang besar, energi listrik yang besar, dan tentunya biaya jadi lebih mahal. Pada penelitian ini, dilakukan alternative proses pengelasan dengan teknik Temper bead welding, pada sambungan frame bogie plate to plate dan plate to round bar. Selain itu juga melakukan proses Post Weld Heat Treatment pada sambungan plate to plte, dan sequence of welding pada sambungan plate to round bar. Hasil penelitian menunjukkan, bahwa proses Temper bead welding yang dilakukan terhadap proses fabrikasi joint bogie LRT plate to plate dan joint plate to round bar, dapat menurunkan nilai kekerasan, namun belum menunjukkan perbedaan yang signifikan. Sedangkan proses Temper bead welding dapat menghasilkan distorsi yang paling kecil pada bogie LRT. Hasil pengukuran distrosi menujukan pengelasan sequence B menghasilkan distorsi paling besar, sedangkan variasi distorsi terkecil adalah varisi sequence $\mathrm{C}$ dengan temper bead welding.
\end{abstract}

Kata Kunci: Welding sequence, Temper bead welding, Distorsi, kekerasan

\section{PENDAHULUAN}

PT. INKA (Industri Kereta Api), merupakan salah satu Badan Usaha Milik Negara (BUMN) yang bergerak dalam bidang fabrikasi kereta api, Perusahaan terus mengembangkan kemampuannya dalam memproduksi kereta api sesuai kebutuhan era 
sekarang, terbukti dengan tender LRT Jakrta Palembang yang telah dimenangkan oleh PT. INKA Hal ini membuktikan bahwa PT. INKA sudah teruji mampu membuat kereta api, tidak hanya untuk kebutuhan dalam negeri, namun juga sudah melakukan ekspor produk kereta api, ke beberapa Negara, seperti, Malaysia, Thailand dan Bangladesh. Dalam proses fabrikasi kereta api, kualitas dan kelayakan produk menjadi salah satu instrument penting dalam proses produksinya. Salah satu bagian penting dalam proses produksi kereta api adalah proses pengelasan. Proses pengelasaan salah satu proses penyambungan yang digunakan dalam proses produksi di PT. INKA.

Dalam proses produksi kereta api, proses yang mendapat pengawasan secara khusus dari divisi pengendalian kualitas adalah proses pembuatan bogie kereta api. Bogie adalah bagian dari kereta api, dimana terdapat berbagai komponen seperti roda,sistem suspensi, sistem pengereman,serta sebagai penyangga frame pada kereta api yang menerima beban paling besar dan berhubungan dengan safety, sehingga bagian bogie ini membutuhkan pengawasan khusus dalam proses pembuatanya. Selain pengawasan secara internal dari perusahaan fabrikasi kereta api, juga mendapat pengawasan langsung dari perusahaan jasa inspeksi sebagai perwakilan dari pemilik lisensi bogie kereta api yang akan dibuat, yaitu sebuah perusahaan internasional asal Jerman, selaku pemilik lisensi bogie yang digunakan oleh perusahaan fabrikasi kereta api.

Dalam proyek LRT (Light Rail Transit), untuk menyambut Sea Games Palembang tahun 2018, proses pembuatan kontruksi bogie keretaapi dilakukan di PT. INKA adalah design bogie baru, material yang digunakan adalah baja carbon rendah SM 490 dengan mengunakan prosess las GMAW (Gas Metal Arc Welding). Produk bogie yang telah selesai dilas, kemudian dilakukan proses anealing yang bertujuan untuk mengurangi tegangan sisa, kekerasan material dan memperbaiki struktur mikro akibat proses pengelasan. Anealing (post weld heat treatment/PWHT) dilakukkan pada bogie dengan memanaskan pada tempertur $650^{\circ}$ lalu ditahan selama 6 jam. Proses annealing (PWHT) terhadap bogie secara keseluruhan, membutuhkan furnace dan energy listrik yang besar. Oleh karena harus ada metode yang dapat mensubstitusi proses annealing/PWHT yang bertujuan untuk mereduksi residual stress, dan menurunkan tingkat kekerasan yang dihasilkan, serta meningkatkan ketangguhan konstruksi bogie.

Alternatif substitusi proses PWHT yang telah di rekomendasikan oleh standar ASME IX, adalah metode TBW (Temper bead welding). Definisi dari temper bead welding sesuai artikel pada ASME Section IX-QG 109, dengan definisi: "Temper bead welding: a weld bead placed at a specific location in or at surface of a weld for purpose of affecting the metallurgical properties of the heat affected zone or previously deposited weld metal. "(ASME SEC.IX, 2015) . Pada ASME code QW-2002.2 Welding proces restriction, diatur tentang batasan proses pengelasan yang di ijinkan, artinya tidak semua proses pengelasan bisa digunakan untuk aplikasi proses temper bead welding. Temper bead welding dibatasi pada proses pengelasan SMAW, GTAW, GMAW, FCAW.

Menurut WTIA material yang dapat diaplikasikan temper bead welding terbatas pada carbon steel dan low alloy steel. Untuk low alloy steel dibatasi pada material dengan kandungan Crhomium maksimum $2.25 \%$ dan Molydenum maksimum 1\%. (Walter J. Spektro : 2005).

Untuk mengoptimasi sifat dari lasan, dimana PWHT tidak dapat dilakukan atau dapat dilakukan namun terhalang sesuatu, maka teknik TBW dapat dilakukan sebagai alternatif (Walter J. Spektro : 2005). Pada teknik TBW, setelah layer pertama dilakukan kemudian melakukan layer berikutnya, maka efek tempering yang ada pada layer kedua tidak hanya mempengaruhi bead pada layer kedua saja tetapi juga pada layer pertama.

Penelitian tentang Temper bead welding pernah dilakukan oleh Yogi Ardyansah , 2012, Aplikasi TBW untuk menggantikan PWHT pada sambungan Stub To Harp Nozzle dengan material SA335 P22 to SA 106C di PT. ALSTOM POWER ESI Surabaya, hasil dari penelitian tersebut membuktikan bahwa TBW bisa menurunkan residual stress, dan kekerasan pada sambungan Stub to harp nozzle.

Moh. Alihsan Arisandi, 2013, melakukan penelitian, pengaruh temper bead welding pada pengelasan material SA 516-70 terhadap ketangguhan, kekerasan dan struktur mikro, hasilnya menunjukkan bahwa kekerasan pada sambungan las baik di daerah HAZ, dan Weld metal mengalami penurusan nilai kekerasan, sedangkan pengujian impact pada suhu ruangan, Impact strength pada proses PWHT dan Temper bead welding terjadi perbedaan sebesar $0.07 \mathrm{~J} / \mathrm{mm}^{2}$. Sehingga Temper bead welding bisa sebagai alternatif pengganti proses PWHT.

Abdul Kareem S, Alorair, et.al, (ASM International 2014), melakukan penelitian terhadap material A105 yang dilakukan pengelasan Temper bead welding, untuk melihat pengaruh proses tersebut terhadap perubahan struktur mikro, hardness, dan residual stressnya. Hasil dari proses tersebut menunjukkan bahwa PWHT dan TBW menghasilkan kekerasan yang memenuhi persyaratan sesuai dengan standard Australia AS2205.61-97 yang nilai nya kurang dari 300 HVN. Namun dari hasil pengujian residual stress, metode TBW masih menghasilkan pengurangan residual stress yang tidak terlalu besar. 
Kuo-Hsia Ling, et.al 2015, melakukan penelitian terhadap material SS400 dengan Temper bead welding, menggunakan variasi multipass temper bead welding, dengan variasi 4 pass 4 layer dan 4 pass 10 layer. Dari penelitian yang telah dilakukan menghasilkan penurunan nilai kekerasan di daerah HAZ dan weld metal, serta meningkatkan ketangguhannya, dari pengamatan struktur mikro didapatkan struktur ferrite dan acicular ferrite, yang membuktikan hasil dari proses tempering pada daerah HAZ.

Proses pengelasan sambungan plate to plate dan plate to round bar, yang terdapat pada konstruksti bogie LRT, seperti ditunjukkan pada Gambar 1 berikut:

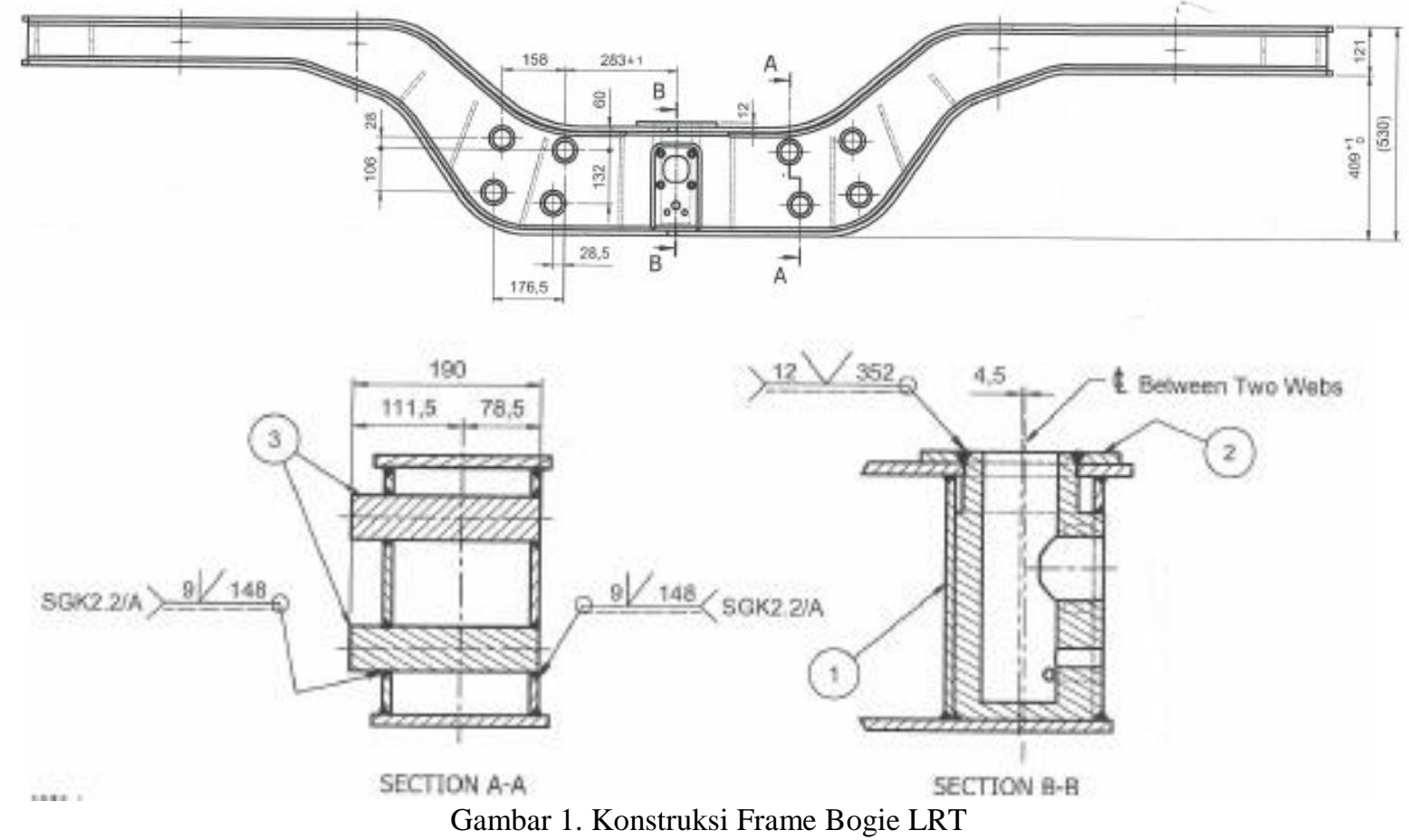

Pengelasan dilakukan dengan mengatur welding sequence dan temper bead welding pada penyambungan plate to round bar, sedangan pada pengelasan plate to plate pengelasan di ikuti dengan proses PWHT dan alternatih pengelasan dengan temper bead welding. Hal ini dilakukan sebagai upaya untuk menemukan alternative pengganti annealing/PWHT agar proses produksi bogie lebih efisien.

\section{METODOLOGI PENELITIAN}

Penelitian dilakukan dengan melakukan proses pengelasa pada material yang digunakan pada bogie SM 490 JIS G3106 carbon steel, dengan tebal 12 $\mathrm{mm}$ sedangkan round bar dengan diameter $115 \mathrm{~mm}$. SM 490 termasuk jenis baja karbon rendah yang mempunyai kandungan kimia dan mechanical properties seperti ditunjukkan pada seperti ditunjukkan pada Tabel 1 dan Tabel 2, berikut:

Tabel 1. Komposisi kimia Material SM490

\begin{tabular}{ccccccccccc}
\hline Grade & \multicolumn{10}{c}{ Komposisi Kimia (\%) } \\
\cline { 2 - 12 } Baja & $\mathrm{C}$ & $\mathrm{Mn}$ & $\mathrm{Ni}$ & $\mathrm{Si}$ & $\mathrm{P}$ & $\mathrm{S}$ & $\mathrm{N}$ & $\mathrm{Mo}$ & $\mathrm{Ti}$ & $\mathrm{Nb}$ \\
\hline SM490 & 0.160 & 1.400 & 0.010 & 0.200 & 0.013 & 0.070 & 0.003 & 0.001 & 0.003 & 0.041 \\
\hline
\end{tabular}

Sumber: Data sekunder yang diolah, Tahun 2017

Tabel 2. Mechanical Properties SM 490

\begin{tabular}{lc}
\hline Sifat Mekanik & Nilai \\
\hline Yield strength & $459 \mathrm{MPa}$ \\
Tensile strength & $565 \mathrm{MPa}$ \\
Elongation & $22 \% \mathrm{~min}$ \\
\hline
\end{tabular}

Sumber: Data sekunder yang diolah, Tahun 2017

Pada proses pengelasan plate to plate dilakukan dengan variable, tanpa perlakuan,
PWHT dan TBW, parameter pengelasan untuk variable tanpa perlakuan dan PWHT ditunjukkan 
pada Tabel 3 sedangkan variable PWHT

ditunjukkan pada Tabel 4.

Tabel 3. Parameter pengelasan untuk variable tanpa perlakuan dan PWHT

\begin{tabular}{cccccccc}
\hline $\begin{array}{c}\text { Proses } \\
\text { las }\end{array}$ & Bead & $\begin{array}{c}\text { Diameter } \\
\text { elektroda } \\
(\mathbf{m m})\end{array}$ & Layer & Arus (A) & $\begin{array}{c}\text { Voltase } \\
(\mathbf{V})\end{array}$ & $\begin{array}{c}\text { Travel } \\
\text { speed } \\
(\mathbf{m m} / \mathbf{m e n i t})\end{array}$ & $\begin{array}{c}\text { Heat input } \\
(\mathbf{J} / \mathbf{m m})\end{array}$ \\
\hline GMAW & 1 & 0,8 & 1 & 125,3 & 23,5 & 220 & 803,05 \\
& 2 & 1,2 & 2 & 242,7 & 23,4 & 253 & 1346,84 \\
& 3 & 1,2 & 3 & 248 & 23,4 & 257 & 1354,83 \\
\hline
\end{tabular}

Sumber: Data primer yang diolah, Tahun 2017

Tabel 4. Parameter pengelasan untuk variable TBW

\begin{tabular}{cccccccc}
\hline Proses las & Bead & $\begin{array}{c}\text { Diameter } \\
\text { elektroda } \\
(\mathbf{m m})\end{array}$ & Layer & $\begin{array}{c}\text { Arus } \\
(\mathbf{A})\end{array}$ & $\begin{array}{c}\text { Voltase } \\
(\mathbf{V})\end{array}$ & $\begin{array}{c}\text { Travel speed } \\
(\mathbf{m m} / \mathbf{m e n i t})\end{array}$ & $\begin{array}{c}\text { Heat } \\
\text { input } \\
(\mathbf{J} / \mathbf{m m})\end{array}$ \\
\hline GMAW & 1 & 0.8 & 1 & 128,7 & 23,4 & 257 & 703,09 \\
& 2 & 1.2 & 2 & 160,9 & 23,9 & 277 & 832,9 \\
& 3 & 1.2 & 3 & 213,5 & 23,9 & 290,4 & 1054,2 \\
& 4 & 1.2 & 4 & 274,5 & 23,9 & 315,8 & 1246.5 \\
\hline
\end{tabular}

Sumber: Data primer yang diolah, Tahun 2017

Proses pengelasan plate to round bar dilakukan dengan sequence dan parameter pengelasan seperti ditunjukkan pada Gambar 2 untuk sequence $\mathrm{A}$ dan sequnce $\mathrm{C}$, sedangkan parameter pengelasan sequence A ditunjukkan pada Tabel 5. Pada proses pengelasan sequence $\mathrm{B}$ ditunjukkan pada Gambar 3, parameter pengelasan sequence $\mathrm{B}$ ditunjukkan pada Tabel 6 . Pada proses pengelasan dengan temper bead welding, parameter pengelasannya ditunjukkan pada Tabel 7.

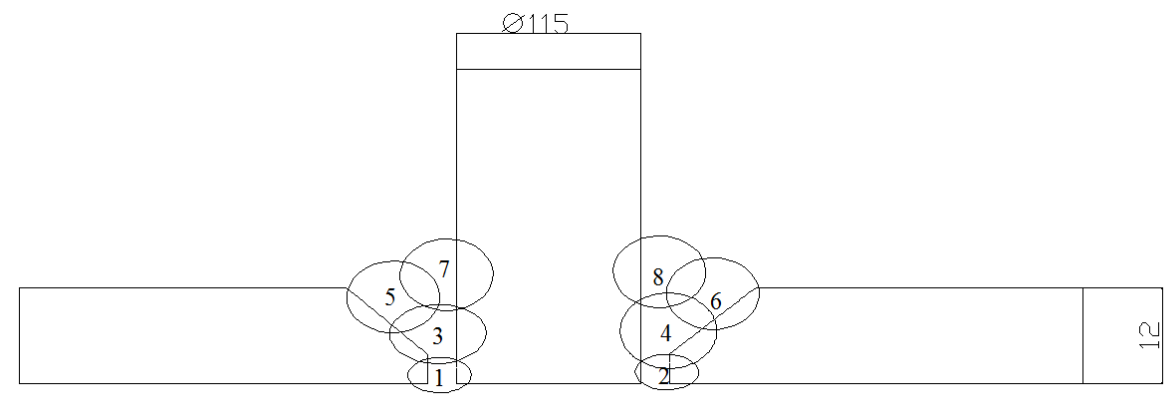

Gambar 2. Welding sequence untuk sequence A dan sequence C (TBW)

Tabel 5. Parameter pengelasan untuk sequence A

\begin{tabular}{cccccccc}
\hline Proses & Posisi & Pass & $\begin{array}{c}\text { Diameter } \\
\text { Elektoda } \\
(\mathbf{m m})\end{array}$ & $\begin{array}{c}\text { Ampere } \\
(\mathbf{A})\end{array}$ & $\begin{array}{c}\text { Voltage } \\
(\mathbf{V})\end{array}$ & $\begin{array}{c}\text { Traveel } \\
\text { Speed } \\
(\mathbf{c m} / \mathbf{m e n i t})\end{array}$ & $\begin{array}{c}\text { Heat Input } \\
(\mathbf{J} / \mathbf{m m})\end{array}$ \\
\hline & 1 & root & 1.2 & 233.5 & 25.8 & 34.14 & 1058.75 \\
& 2 & root & 1.2 & 225.8 & 25.4 & 30.31 & 1135.33 \\
GMAW & 3 & Filler & 1.2 & 239 & 25.9 & 34.14 & 1087.89 \\
& 4 & filler & 1.2 & 236.5 & 25.5 & 30.84 & 1173.29 \\
& 5 & caping & 1.2 & 247.7 & 25.9 & 35.52 & 1083.68 \\
& 6 & caping & 1.2 & 253.4 & 25.7 & 30.84 & 1267.00 \\
& 7 & caping & 1.2 & 250.3 & 25.6 & 34.14 & 1126.13 \\
& 8 & caping & 1.2 & 257 & 25.9 & 32.56 & 1226.59 \\
\hline
\end{tabular}

Sumber: Data primer yang diolah, Tahun 2017 


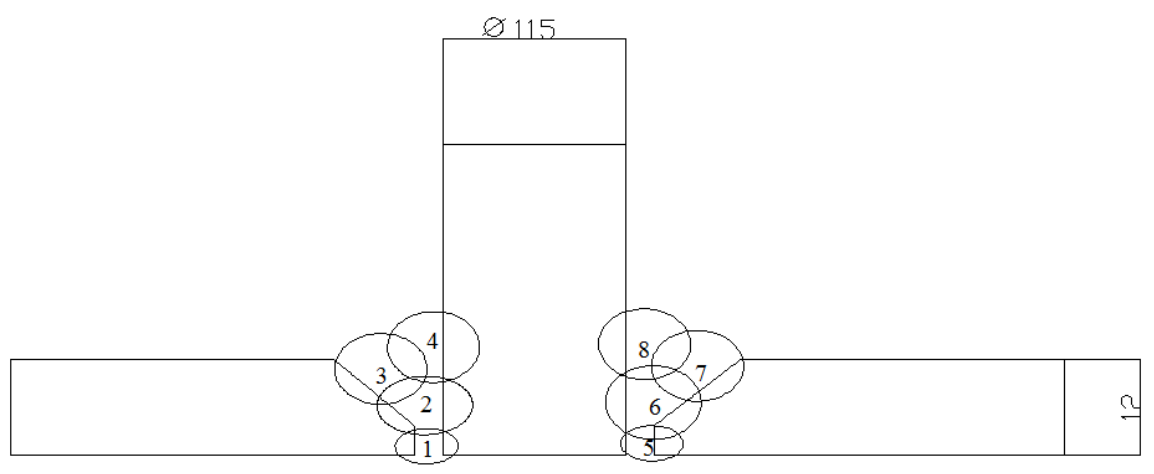

Gambar 3 Welding sequence untuk sequence B

Tabel 5. Parameter pengelasan untuk sequence B

\begin{tabular}{lclccccc}
\hline Proses & Posisi & Pass & $\begin{array}{c}\text { Diameter } \\
\text { Elektoda } \\
(\mathbf{m m})\end{array}$ & $\begin{array}{c}\text { Ampere } \\
(\mathbf{A})\end{array}$ & $\begin{array}{c}\text { Voltage } \\
(\mathbf{V})\end{array}$ & $\begin{array}{c}\text { Traveel } \\
\text { Speed } \\
(\mathbf{c m} / \mathbf{m e n i t})\end{array}$ & $\begin{array}{c}\text { Heat Input } \\
(\mathbf{J} / \mathbf{m m})\end{array}$ \\
\hline & 1 & root & 1.2 & 221.1 & 25.1 & 30.31 & 1098.57 \\
& 2 & filler & 1.2 & 237.3 & 25.9 & 31.17 & 1183.07 \\
GMAW & 3 & caping & 1.2 & 246.8 & 26.6 & 30.84 & 1277.21 \\
& 4 & caping & 1.2 & 253 & 26.8 & 32.86 & 1238.05 \\
& 5 & root & 1.2 & 228.3 & 258 & 31.4 & 1125.50 \\
& 6 & filler & 1.2 & 241.5 & 25.9 & 34.47 & 1088.74 \\
& 7 & caping & 1.2 & 242.6 & 26.6 & 29.8 & 1299.29 \\
& 8 & caping & 1.2 & 244.5 & 26.9 & 33.17 & 1189.69 \\
\hline
\end{tabular}

Sumber: Data primer yang diolah, Tahun 2017

Tabel 5. Parameter pengelasan untuk sequence $\mathrm{C}$ (TBW)

\begin{tabular}{lclccccc}
\hline Proses & Posisi & Pass & $\begin{array}{c}\text { Diameter } \\
\text { Elektoda } \\
(\mathbf{m m})\end{array}$ & $\begin{array}{c}\text { Ampere } \\
(\mathbf{A})\end{array}$ & $\begin{array}{c}\text { Voltage } \\
(\mathbf{V})\end{array}$ & $\begin{array}{c}\text { Traveel } \\
\text { Speed } \\
(\mathbf{c m} / \mathbf{m e n i t})\end{array}$ & $\begin{array}{c}\text { Heat Input } \\
(\mathbf{J} / \mathbf{m m})\end{array}$ \\
\hline & 1 & root & 1.2 & 215.8 & 25.5 & 29.8 & 1107.96 \\
GMAW & 2 & root & 1.2 & 215.8 & 25.5 & 31.4 & 1051.50 \\
& 3 & filler & 1.2 & 276.8 & 29.1 & 34.47 & 1402.06 \\
& 4 & iller & 1.2 & 280.5 & 29.3 & 33.81 & 1458.50 \\
& 5 & caping & 1.2 & 343.1 & 31.1 & 30.31 & 2112.25 \\
& 6 & caping & 1.2 & 342.8 & 31.4 & 30.84 & 2094.14 \\
& 7 & caping & 1.2 & 347.7 & 31.1 & 33.81 & 1918.98 \\
\hline
\end{tabular}

Sumber: Data primer yang diolah, Tahun 2017

\section{HASIL DAN PEMBAHASAN}

Dari hasil pengujian kekerasan yang telah dilakukan, pada pengelasan plate to plate, distribusi kekerasan pada bagian root pass, ditunjukkan pada Gambar 4, bagian hot pass ditunjukkan pada Gambar 5, dan bagian cap pass ditunjukkan pada Gambar 6. 


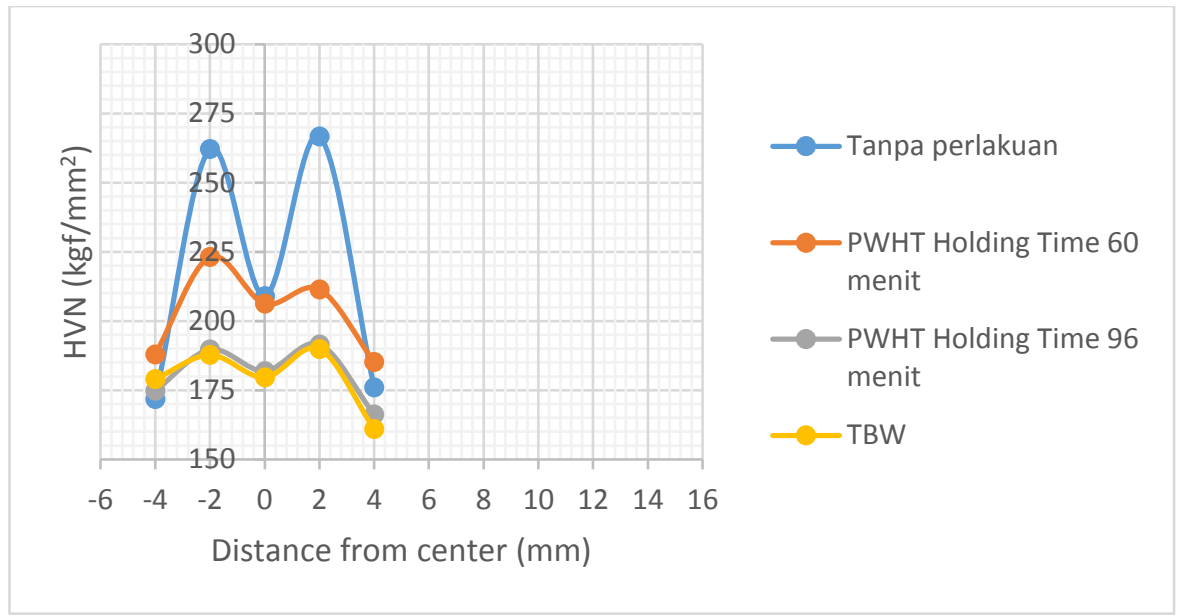

Gambar 5. Distribusi kekerasan pada bagian root pass

Dari distribusi kekerasan tersebut, terlihat bahwa TBW memberikan dampak terhadap penurunan nilai kekerasan, karena dengan melakukan TBW dapat memebrikan efek tempering pada daerah HAZ, sehingga menurunkan nilai kekerasannya. Hal ini disebabkan karena efek tempering dapat mereduksi residual stress yang terjadi pada daerah HAZ.

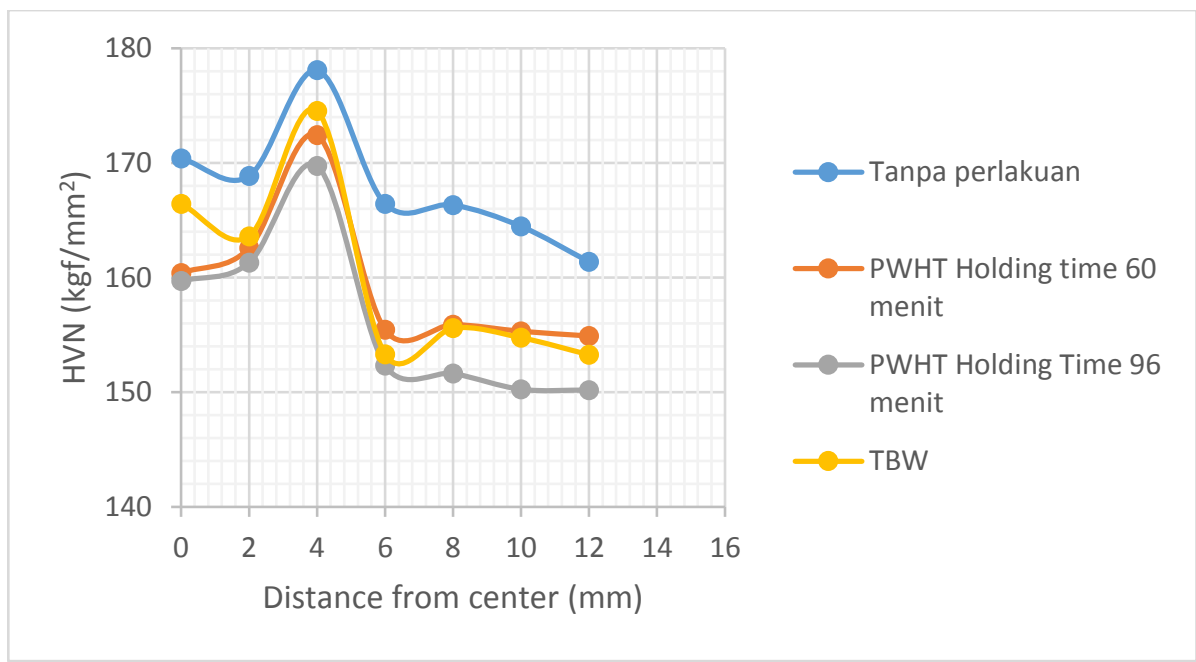

Gambar 6. Distribusi kekerasan pada bagian hot pass

Sumber : Data primer yang diolah, Tahun 2017

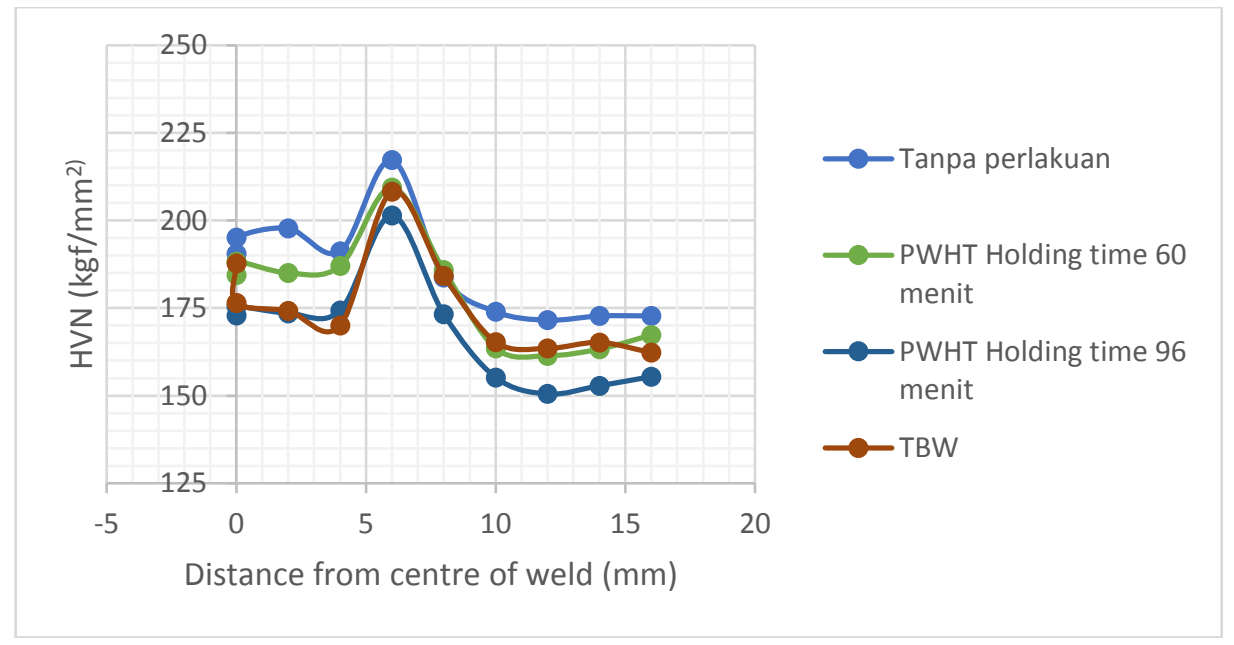

Gambar 7. Distribusi kekerasan pada bagian cap pass

Sumber: Data primer yang diolah, Tahun 2017 
Efek yang diakibatkan oleh proses TBW, hampir sama dengan efek yang diakibatkan oleh PWHT. Kedua proses tersebut bertujuan untuk mereduksi kekerasan yang tinggi terutama pada daerah HAZ, sebab daerah HAZ memiliki kergaman struktur mikro yang diakibatkan oleh pemanasan saat dilakukan proses pengelasan. Hal tersebut dapat dilihat pada distribusi kekerasan yang terjadi pada daerah hot pass dan cap pass.

Hasil pengelasan plate to round bar, dengan variasi 3 welding squences, menghasilkan distribusi kekerasan seperti terlihat pada Gambar 8 berikut

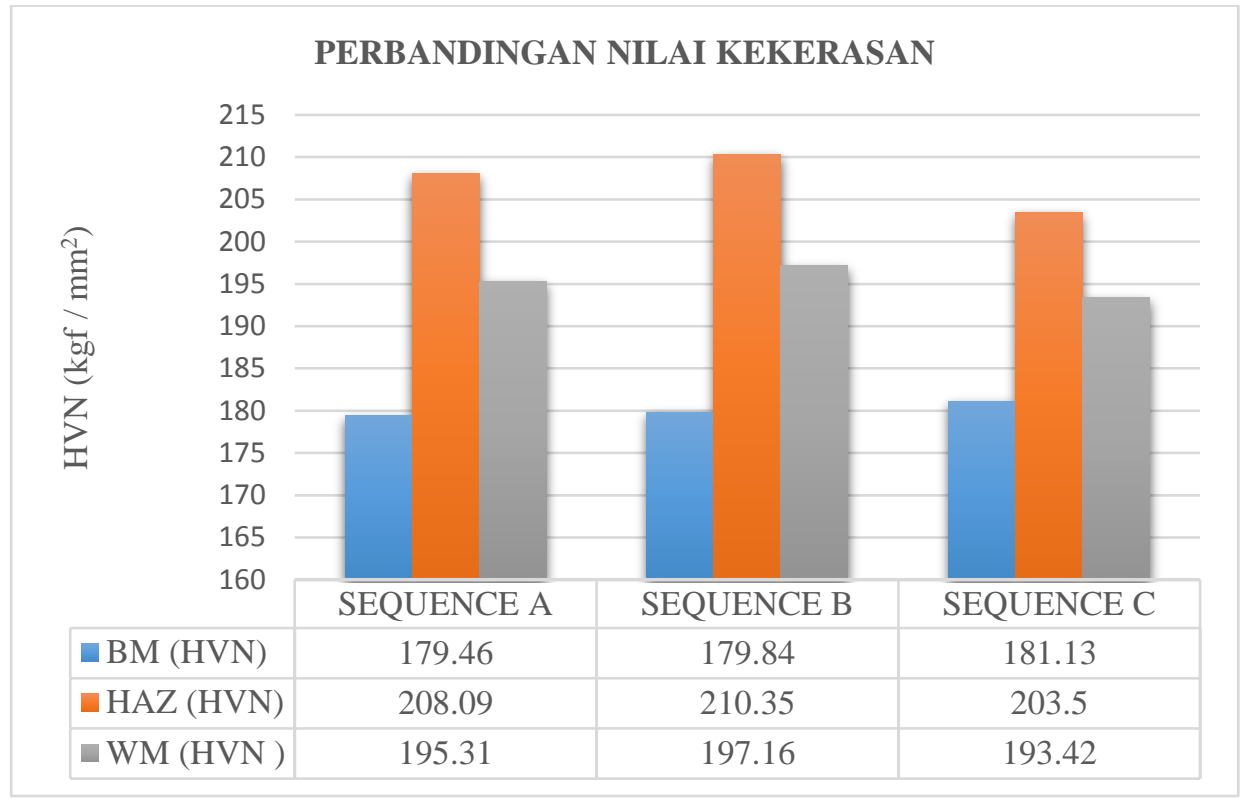

Gambar 8. Hasil uji kekerasan pada pengelasan plate to round bar Sumber: Data primer yang diolah, Tahun 2017

Dari hasil pengujian kekerasan pada pengelasan plate to round bar, dengan variasi 3 welding squences, pada sequence $\mathrm{C}$, dengan melakukan TBW, dapat menghasilkan nilai kekerasan yang paling rendah pada daerah HAZ dibandingkan dengan sequence A dan sequence $\mathrm{B}$. Hal ini disebabkan karena TBW dilakukan dengan memberikan heat input yang lebih besar, sehingga efek tempering pada layer sebelumnya menjadi lebih besar, akibat nya nilai kekerasannya menjadi lebih rendah. Hasil pengujian distorsi yang terjadi pada proses pengelasan plate to round bar, ditunjukkan pada Tabel 6 berikut:

Tabel 6. Hasil pengukuran distorsi pengelasan plate to round bar

\begin{tabular}{|c|c|c|c|c|c|c|c|c|c|}
\hline Specimen & A1 & A2 & A3 & B1 & B2 & B3 & C1 & $\mathrm{C2}$ & C3 \\
\hline $\begin{array}{c}\text { Besar distorsi } \\
\left(\text { Derajat } /{ }^{\circ}\right) \\
\text { Rata-rata } \\
\left(\text { Derajat } /^{\circ}\right)\end{array}$ & 0.7 & 0.6 & 0.4 & 1.3 & 2.3 & 2.1 & 0.4 & 0.5 & 0.6 \\
\hline
\end{tabular}

Sumber: Data primer yang diolah, Tahun 2017

Terlihat bahwa proses TBW selain dapat menurunkan kekerasan di daerah HAZ, juga memebrikan efek distorsi yang paling kecil, hasil disebabkan pengaturan sequence pengelasan dapat mengontrol besarnya distorsi yang terjadi.
Hasil pengujian struktur mikro dari material SM 490, memperlihatkan struktur mikro elongated grain yang terjadi pada base metal, dengan fasa ferrite (terang) dan pearlite (gelap), seperti ditunjukkan pada Gambar 8. Bentuk struktur elongated grain searah dengan proses pengerolan plat 


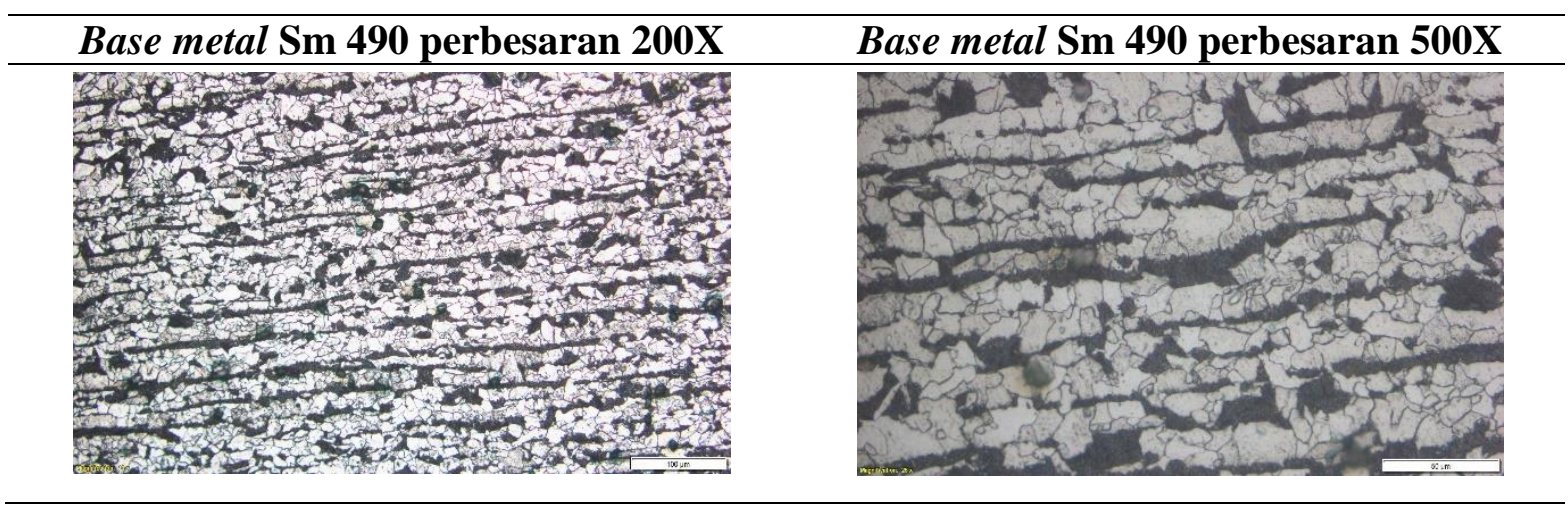

Gambar 8. Struktur mikro base metal SM 490

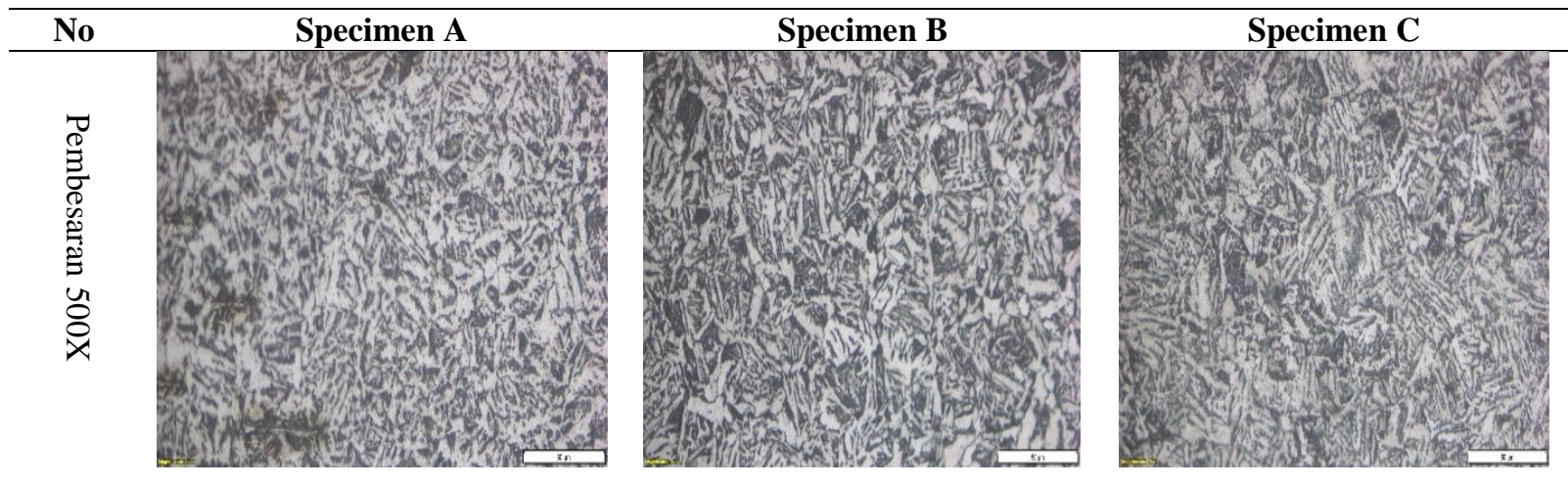

Gambar 9. Struktur mikro daerah HAZ

Daerah HAZ, ditunjukkan pada Gambar 9, HAZ (heat affected zone) atau daerah terpengaruh panas, daerah ini merupakan daerah yang mengalami perubahan struktur mikro, sehingga daerah ini memiliki sifat mekanik/kekerasan yang beragam. Hal ini disebabkan daerah ini mengalami pemanasan mulai temperatur di atas temperatur kritis $\left(730^{\circ} \mathrm{C}\right)$ sampai temperature partial melting zone, dengan bentuk butiran austenite yang mengalami grain growth. Dari ketiga welding squences, menunjukkan bentuk struktur mikro yang hamper sama, struktur tersebut disebabkan tempatur yang tinggi, sehingga austenite mengalami grain coarsening, akibat pendingan yang terjadi terbentuk ferrite widmanstaten, yang tumbuh dari batas butir.

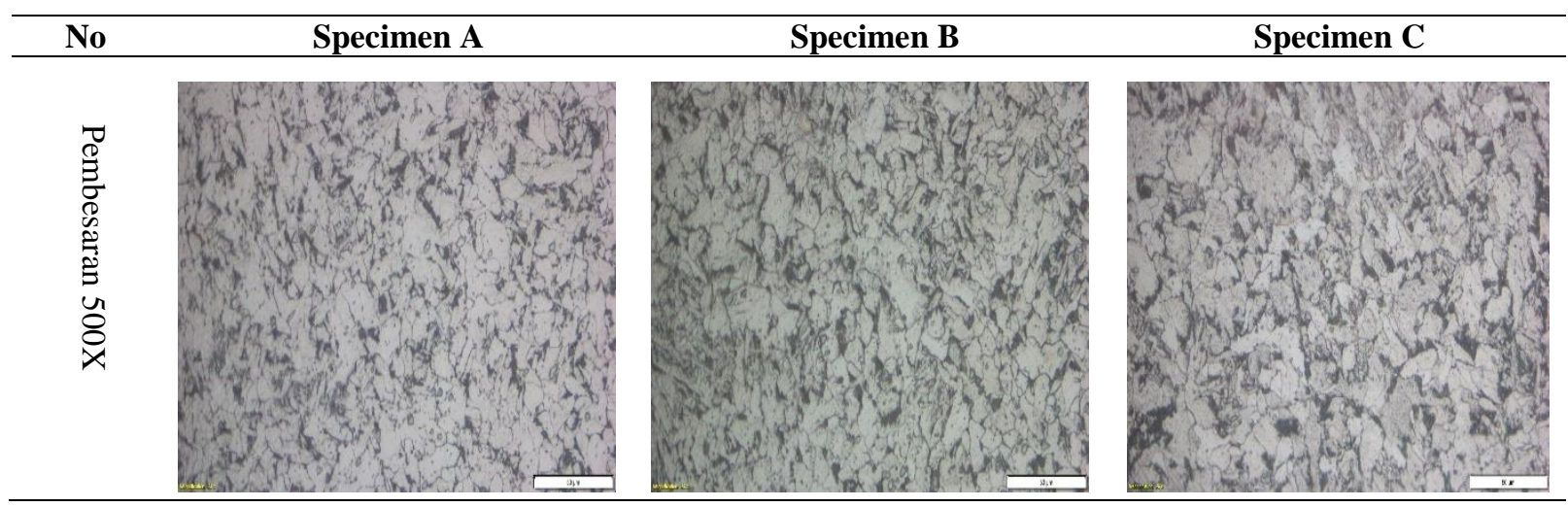

Gambar 10. Struktur mikro daerah weld metal

Sumber: Data primer yang diolah, Tahun 2017

Pada daerah weld metal, ditunjukkan pada Gambar 10, hasil pendinginan daerah yang mengalami pencairan saat pengelasan, pada baja karbon rendah, peluang terbentuk struktur 
martensite maupun binit sangan sulit terjadi, sehingga struktur yang mungkin terjadi adalah ferrite dengan beragam bentuknya.

\section{DAFTAR PUSTAKA}

1. Abdul Kareem, A. e. (2014). Hardness, Microstructure, and Residual Stresses in Low Carbon Steel Welding with Post Weld Heat Treatment and Temper bead welding. Metalurgical And Materials Transactions.

2. Andriansyah, y. (2012). Aplikasi temper bead welding (TBW) Untuk Menggantikan Proses Post weld Heat Treatment Pada Sambungan Stub to Harp Nozzle dengan Material SA 335 P22 to SA 106 C di PT Alstom Power ESISurabaya. Surabaya: PPNS.

3. Arisandi, M. A. (2013). Pengaruh Teknik Temper bead welding pada pengelasan
Material SA 516 Grade 70 sebagai Pengganti PWHT terhadap Toughness, hardness dan Struktur Mikro. Surabaya: PPNS.

4. ASME. (2015). ASME Boiler and Pressure Vessel Code Section IX: Welding And Brazing Qualification. New York: ASME.

5. Australia, W. T. (2006). Temper bead welding. WTIA.

6. Kuo-Hsi Ling, e. (2015). Effect of welding Squence of Multi pass Temper bead in Gas Shielded Flux Core Arc welding Process: Hardness, Micro Structure, and Impact Toughneess Analysis. internationan Journal advanched manufacturing Technology, 1033 1046.

7. Sperko, W. J. (2015). Exploring Temper bead welding. Welding Journal, American welding Society. 